\title{
Aircraft induced contrail cirrus over Europe
}

\author{
HERMANN MANNSTEIN* and ULRICH SCHUMANN
}

Deutsches Zentrum für Luft- und Raumfahrt (DLR), Institut für Physik der Atmosphäre, Oberpfaffenhofen, Germany

(Manuscript received January 12, 2004; in revised form October 4, 2004; accepted March 29, 2005)

\begin{abstract}
Condensation trails (contrails) and aircraft induced cirrus are nowadays a common feature at the mid latitude skies. Previously the impact of aircraft induced cirrus changes has been roughly estimated from observed decadal trends in cirrus cover but the direct attribution of observed cirrus changes to changes in aviation activity remains uncertain. In this paper the amount of additional cirrus induced from spreading contrails in humid air is estimated from the direct correlation between observed cirrus cover derived with suitable methods from METEOSAT data and aviation flight density reported by EUROCONTROL at high spatial and temporal resolution from June 22 to July 27, 1998 and September 27 to October 21, 2000. The results indicate that the aircraft induced cirrus cover over Europe is about ten times larger than that of linear contrails in the same region. Radiative forcing from the additional cirrus may be more than 10 times higher than that of linear contrails and aviation induced $\mathrm{CO}_{2}$ increases.
\end{abstract}

\begin{abstract}
Zusammenfassung
Kondensstreifen und vom Flugverkehr verursachte Zirren gehören zu den alltäglichen Erscheinungen am Himmel unserer Breiten. Die vom Flugverkehr verursachte Änderung der Zirrusbewölkung wurde bisher über Trendanalysen der vergangenen Jahrzehnte abgeschätzt. Dennoch blieb der direkte Anteil des Flugverkehrs an den beobachteten Veränderungen der Zirrusbewölkung unsicher. Hier wird der Anteil zusätzlicher Zirren, die aus sich in feuchter Umgebung ausbreitenden Kondensstreifen entstehen, durch eine direkte Korrelation von Bewölkungsdaten aus METEOSAT Bilddaten und Flugverkehrsdaten in hoher räumlicher und zeitlicher Auflösung bestimmt. Die Daten umfassen die Zeiträume 22. Juni bis 27. Juli 1998 und 27. September bis 21. Oktober 2000. Die Ergebnisse deuten an, dass die durch Luftverkehr induzierte Bedeckung mit Zirrus etwa 10 mal größer ist als die linearer Kondensstreifen. Der durch zusätzliche Zirren verursachte Strahlungsantrieb kann mehr als 10 mal größer sein als derjenige, der durch lineare Kondensstreifen oder durch das vom Flugverkehr emittierte $\mathrm{CO}_{2}$ verursacht wird.
\end{abstract}

\section{Introduction}

A contrail forms in the wake of an aircraft if the ambient air is cold and moist enough. The Schmidt-Appleman criterion quantifies the necessary atmospheric conditions (SCHUMANN, 1996). If the ambient air is not supersaturated with respect to ice, the contrail disappears quickly. Otherwise the ice crystals within the contrail grow by uptake of ambient moisture while the contrail is spreading due to turbulence and vertical wind shear (MinNis et al., 1998; SCHUMANN, 2002), forming contrail cirrus that may last several hours, as demonstrated in Fig. 1. In this case the further development of the contrail is governed by the moisture and vertical motion of the ambient air and the sedimentation of the ice particles. Young contrails can be easily identified by their linear appearance (BAKAN et al., 1994; MANNSTEIN et al., 1999), but during their ageing both, their macroscopic structure and their microscopic composition ap-

\footnotetext{
*Corresponding author: Hermann Mannstein, DLR-Institut für Physik der Atmosphäre, Oberpfaffenhofen, 82230 Wessling, Germany, email: Hermann.Mannstein@dlr.de
}

proach that of natural cirrus clouds. Optically thin cirrus has a positive climate impact (LIOU, 1986; BOUCHER, 1999) i.e., it warms the Earth-atmosphere system. In the International Panel on Climate Change (IPCC) Special Report on 'Aviation and the Global Atmosphere' (IPCC, 1999) the impact of linear (young) contrails is estimated to be in the same order of magnitude as the impact caused by emitted $\mathrm{CO}_{2}$; the impact of aircraft induced cirrus (i. e. aged contrails and indirect influence on cirrus formation) is not quantified and the state of scientific understanding of the cirrus changes was assessed to be 'very poor'.

\section{An estimate of contrail cirrus coverage}

Independent from any measurements of cloud coverage the following considerations give a simplified estimate on the influence of air traffic on cirrus coverage: Over Europe in up to $25 \%$ of all cases super-saturation of water vapour with respect to ice is found in measurements performed by instruments operated in the upper troposphere on regular airliners (GIERENS et al., 1999, 2000). 

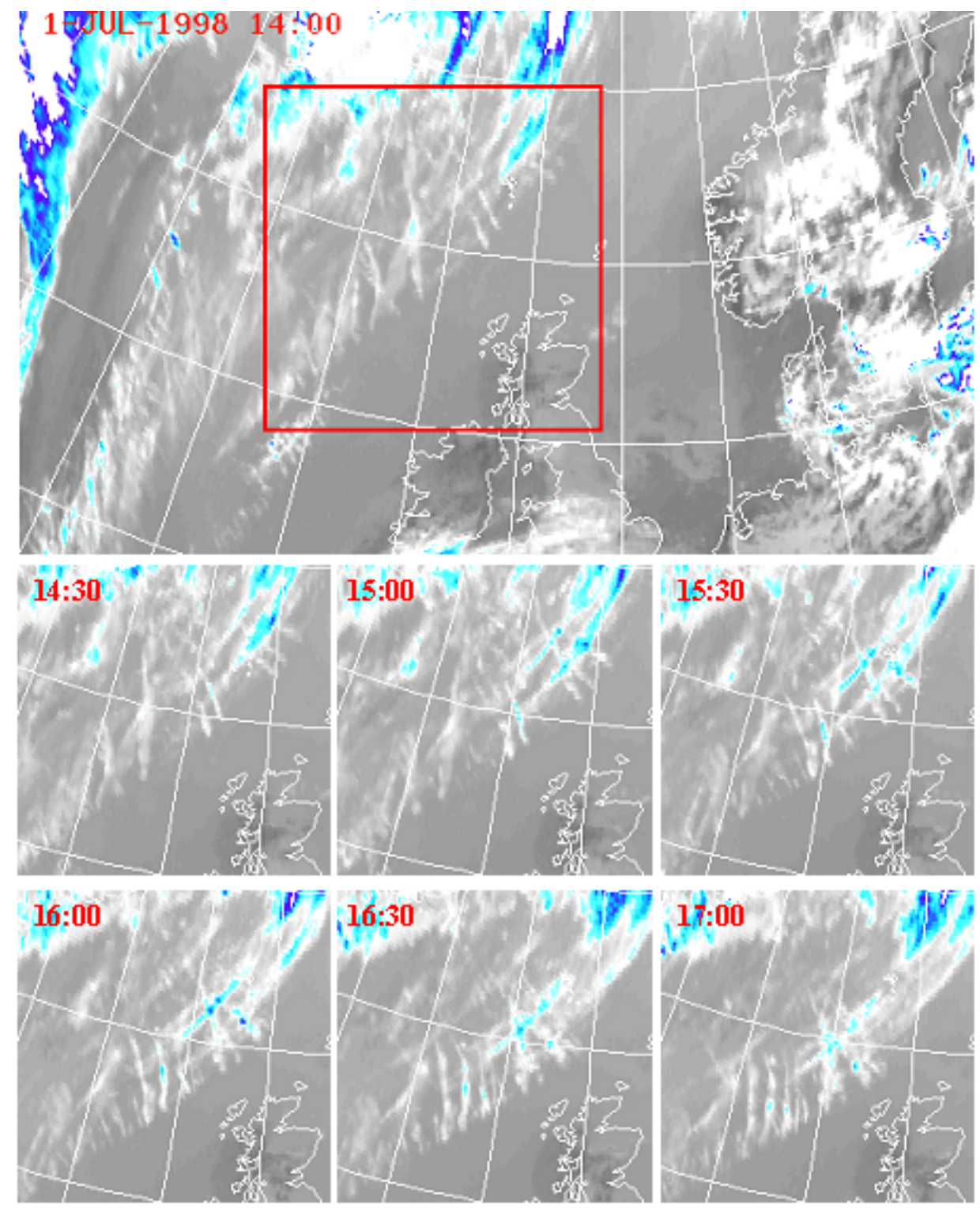

Figure 1: Contrail cirrus in METEOSAT images. Crossing a band of moist air with some cirrus clouds north-west of Scotland, the westbound air traffic on July 1st 1998 left bundles of contrails which remain visible in the METEOSAT infrared channel data for several hours. The blue colors refer to cloud top temperatures less then $-40^{\circ} \mathrm{C}$, time is given in UTC.

In most cases the Schmidt-Appleman criterion for contrail formation is fulfilled within these super-saturated areas. Part of them might be already filled by cirrus clouds or hidden by cirrus layers above, but in the remaining fraction air traffic leads to additional cloud coverage. Here this part of the super-saturated regions is called $C_{p o t}$, the fraction in time and space of the total area with potential contrail coverage.

Horizontal spreading rates $S_{h}$ of contrails between 1 and $8 \mathrm{~km} / \mathrm{h}$ with a mean of about $4 \mathrm{~km} / \mathrm{h}$ are found by FREUDENTHALER et al. (1995) from tracking and scanning contrails with a LIDAR system. Considering a super-saturated air parcel void of any contrails at the beginning, an air traffic density $d$ given in km flight-path per $\mathrm{km}^{2}$ and per hour during a time interval $\Delta t$ leads to total length of contrails of $d \Delta t$ per unit area. The mean width of the contrails is $s_{h} \bar{t}$, where $\bar{t}$ is the mean age of the contrails. Therefore the fractional coverage of spreading contrails is:

$$
c_{f}=d \Delta t s_{h} \bar{t}
$$

Already after $1 \mathrm{~h}$ of air traffic - the mean contrail age is then $1 / 2 \mathrm{~h}-$, the full coverage would be reached with an air traffic density of $=0.5 \mathrm{~km} /\left(\mathrm{km}^{2} \mathrm{~h}\right)$. Therefore an overlap of the evolving cirrus clouds and additional contrails has to be considered. Assuming $\mathrm{N}$ equal contrails, the remaining cloud free part is $1-c_{f}=$ $\left(1-d \Delta t s_{h} \bar{t} / N\right)^{N}$. For random overlap of the contrails, in the limit $N \rightarrow \infty$, the cirrus coverage reads as:

$$
c_{f}=1-e^{-d \Delta t s_{h} \bar{t}}
$$


This approximation is valid, if the area coverage of each single contrail is small compared to the area under consideration and the contrails are randomly oriented. The fractional coverage $c_{f}$ at a given air traffic density $d$ is higher than this approximation if only a few, aligned contrails contribute. Looking for the dependency of $c_{f}$ on $d$, Eq.(2.2) becomes clearer if $\Delta t s_{h} \bar{t}$ is replaced by $1 / d^{*}$, where $d^{*}$ represents the air traffic density leading to a full coverage at a given contrail age, spreading rate, and time interval $\Delta t$, without considering any overlap.

Now the total coverage with cirrus clouds as a function of air traffic density can be written as:

$$
c_{t o t}(d)=c_{0}+c_{\text {pot }}\left(1-e^{-\frac{d}{d^{*}}}\right)
$$

where $c_{0}$ gives the background cirrus coverage without any air traffic.

For longer time-scales the decay of contrail cirrus has also to be considered. From tracking cirrus clusters in METEOSAT data from June and July 1998 we found a half-life time in the order of 2.5 hours, but these data include strong mesoscale convective events and might therefore not represent the lifetime of contrail cirrus. Nevertheless the order of magnitude supports the assumption, that cirrus decay can be neglected at least for the first hour.

\section{Methods to detect cirrus in METEOSAT data}

The main problem in cirrus detection by remote sensing methods is that no natural boundary exists which discriminates cirrus from clear sky. Therefore the amount of detected cirrus depends on the sensitivity of the sensor and the applied algorithm. Different methods will give different absolute values for cirrus coverage. In this study, data from the geostationary METEOSAT satellite are used to derive the cirrus coverage. This satellite is chosen because it combines the possibility to detect cirrus clouds with a high temporal resolution of $30 \mathrm{~min}-$ utes and a reasonably high spatial resolution of approximately $5 \mathrm{~km} \times 9 \mathrm{~km}$ in Western Europe. The resolution is high enough to detect wide contrails, as exemplified in Fig. 1. High clouds, which are usually cirrus clouds, can be detected within the METEOSAT data making use of the water vapour (WV) channel, which has its main sensitivity in the upper troposphere. For this study we use two different specially developed methods. The methods were derived based on plausibility and were tested only qualitatively in some cases by inspecting also the data from the visible channel.

The first method is based on the local spatial correlation between the equivalent blackbody temperatures in the infrared (IR) and the WV channel. A high positive correlation indicates a horizontally structured emitter in the upper troposphere - i.e., a high level cloud.
The correlation coefficient is calculated for each pixel in a $7 x 7$ pixel surrounding weighted with a rotationally symmetric Gaussian filter. A correlation threshold larger than 0.5 is required to discriminate between background noise and clouds. We guess that cirrus clouds with an effective (i.e., related to the pixel size) transmissivity in the visible range larger 0.3 might be detected by this method under favourable conditions. Additionally all pixels with temperatures colder than $-50^{\circ} \mathrm{C}$ are considered to be covered by cirrus clouds. This method will overestimate the cirrus coverage, as gaps are filled, some pixels adjacent to clouds are included, and the sub-pixel structure is not taken into account. On the other hand single young and narrow contrails cannot be detected, as their effect on the thermal emission is far below the sensitivity of the IR and WV sensors of METEOSAT.

The second method has the aim to detect thin cirrus clouds and uses mainly the information in the WV channel: If the standard deviation of the equivalent WV blackbody temperature in a $5 \times 5$ pixel surrounding exceeds the normal noise level of $0.5 \mathrm{~K}$, a cirrus cloud is assumed. Optically thick high and therefore cold clouds, such as deep convective clouds, are excluded by restricting the cirrus cases to IR and WV temperatures higher than $-50^{\circ} \mathrm{C}$. This criterion was chosen to eliminate the possible correlation between deep convective clouds and air traffic, which both occur often during daytime, in particular in the afternoon, over land in summer. This method detects more cirrus clouds than the first method, but has also a higher false alarm rate. The mean values obtained with this method for the observation period are displayed in Fig. 2b. Most misdetections occur in cold mountain regions with dry air above.

\section{Observation of cirrus in air traffic regions}

The direct observation of cirrus clouds resulting from air traffic is currently not possible because we do not know how to separate these clouds from natural cirrus clouds. Nevertheless the dependency of cirrus coverage on air traffic density as given in Eq. (2.3) can be verified. (The possibility that cirrus clouds might have formed in the spreading contrail region in the absence of the initial contrail formation is irrelevant for this study, since such natural cirrus formation would occur in regions with both high and low air traffic density.) Due to the high spatial and temporal variability of air traffic, such a study is only possible with observations from geostationary satellites like METEOSAT. Concerning air traffic data, two data sets of the so called 'corrected scheduled flights' were available from EUROCONTROL, showing the flight path for every commercial flight over Europe defined by the time and altitude of passing way points. The data sets for the two 


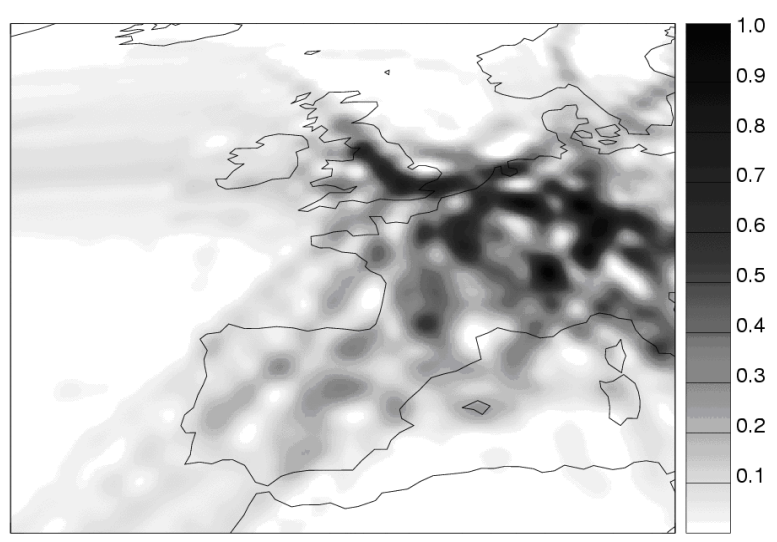

a)

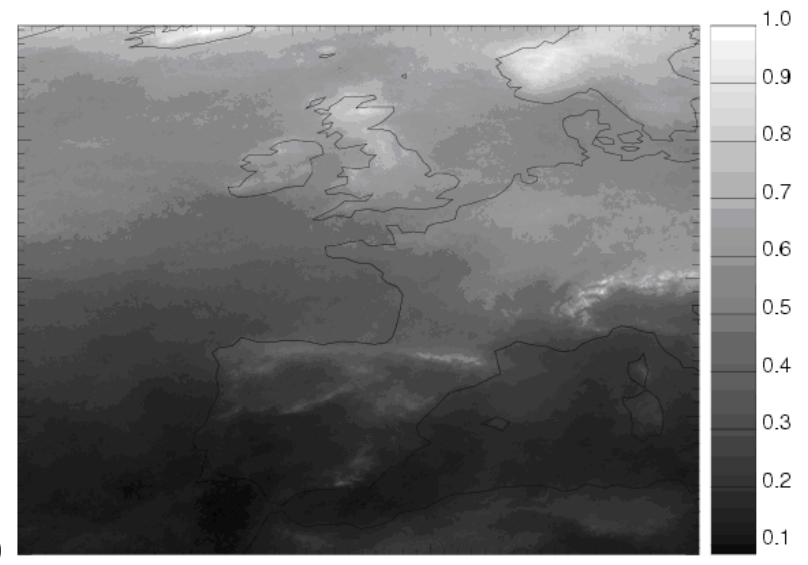

Figure 2: a) Mean air traffic density in June and July 1998. Flight paths above $8 \mathrm{~km}$ altitude according to EUROCONTROL data have been summarised into a $1^{\circ} \mathrm{x} 1^{\circ}$ grid. The air traffic density is given in $\mathrm{km}$ flight path per $\mathrm{km}^{2}$ and per hour. The data is mapped into the METEOSAT projection by interpolation. All results refer to the region displayed here. b) Mean cirrus coverage derived from METEOSAT data for the observation period (June and July 1998, September and October 2000) according to the thin cirrus criterion.

time periods, from June 22 to July 271998 and from September 27 to October 212000 were processed by summarising all flight paths above $8 \mathrm{~km}$ to derive the air traffic density for each hour on a $1^{\circ} \times 1^{\circ}$ grid, see Fig. 2a.

Cirrus coverage was derived with the two methods described above from half hourly METEOSAT data, which was obtained from the 'METEOSAT archive and retrieval facility' (MARF) of EUMETSAT. Figure 3 depicts the cirrus coverage determined by both methods as a function of air traffic density $d$. The data was sampled into 7 classes of air traffic density with logarithmic class boundaries to account for the data distribution. In these figures the air traffic data within each hour is compared to the satellite data at the end of this hour. Therefore a $\Delta t$ of $1 \mathrm{~h}$ and mean contrail age $\bar{t}$ of $1 / 2 \mathrm{~h}$ together with an estimated potential contrail coverage $c_{p o t}$ of 0.2 is used to calculate the expected values. For both methods the cirrus cover increases with $d$ for $d>0$ as expected by Eq. 2.3. An exception is the coverage for the air traffic density class $d=0$. This class comprises nearly $40 \%$ of all pixels and represents the mean cirrus cover in regions in the domain without air traffic, while the class with very low air traffic density $\left(d<0.1 \mathrm{~km} /\left(\mathrm{km}^{2} \mathrm{~h}\right)\right)$, represents the mean cover in the areas with low but finite air traffic. The mean cirrus cover in regions without any air traffic is higher due to the high cirrus coverage at the northern edge of the data-set. Regions with very low air traffic give a better representation of the natural cirrus coverage. Therefore, $c_{0}$ in Eq. (2.3) is matched to result in the same mean cirrus coverage as in the data except for the class with the lowest air traffic density.

With both methods of cirrus detection, the mean cirrus coverage is 0.03 or $3 \%$ higher than $c_{0}$, which results in a $14 \%$ higher cirrus coverage due to air traffic with the first cirrus detection method and in a $11 \%$ increase with the second method (thin cirrus).
As a test of robustness of the statistics, the data set was subdivided into six equal subsets of 10 days each. For five of these subsets the result of the correlation analysis was within a few percent the same as for the whole set; only in one subset a significant correlation could not be found. Independent from any cirrus classification, the equivalent black body temperature measured by the satellite shows also the expected variation with air traffic density. In both channels significantly lower IR temperatures are found at times and in areas with high air traffic density than in low traffic regions (Fig. 3, right). Again the class with air traffic close to zero deviates from the overall picture. Its mean temperature is close to the overall mean temperature and lower than the temperature of the low air traffic classes. A possible reason is that air traffic is positively correlated with land surface and daytime, which is warmer in summer and autumn, so that the infrared signal is higher in the region with high air traffic if not masked by additional cirrus clouds.

\section{Conclusions and outlook}

The analysis of the correlation between cirrus derived from geostationary satellite data and quasi simultaneous air traffic data suggests that air traffic on average over the observation periods induces an additional cirrus cover of $3 \%$ of the Earth surface over Central Europe. BOUCHER (1999) correlated 5-year mean values of cirrus data reported by human observers and mean aviation fuel consumption estimates in $3^{\circ} \times 3^{\circ}$ geographical sub-regions of the Earth. He found higher cirrus increases in regions with high fuel consumption than elsewhere and attributed this effect to aviation induced cirrus. However this and similar long-time statistics cannot exclude that the observed cirrus changes were caused by other changes in the complex Earth system nor by other 

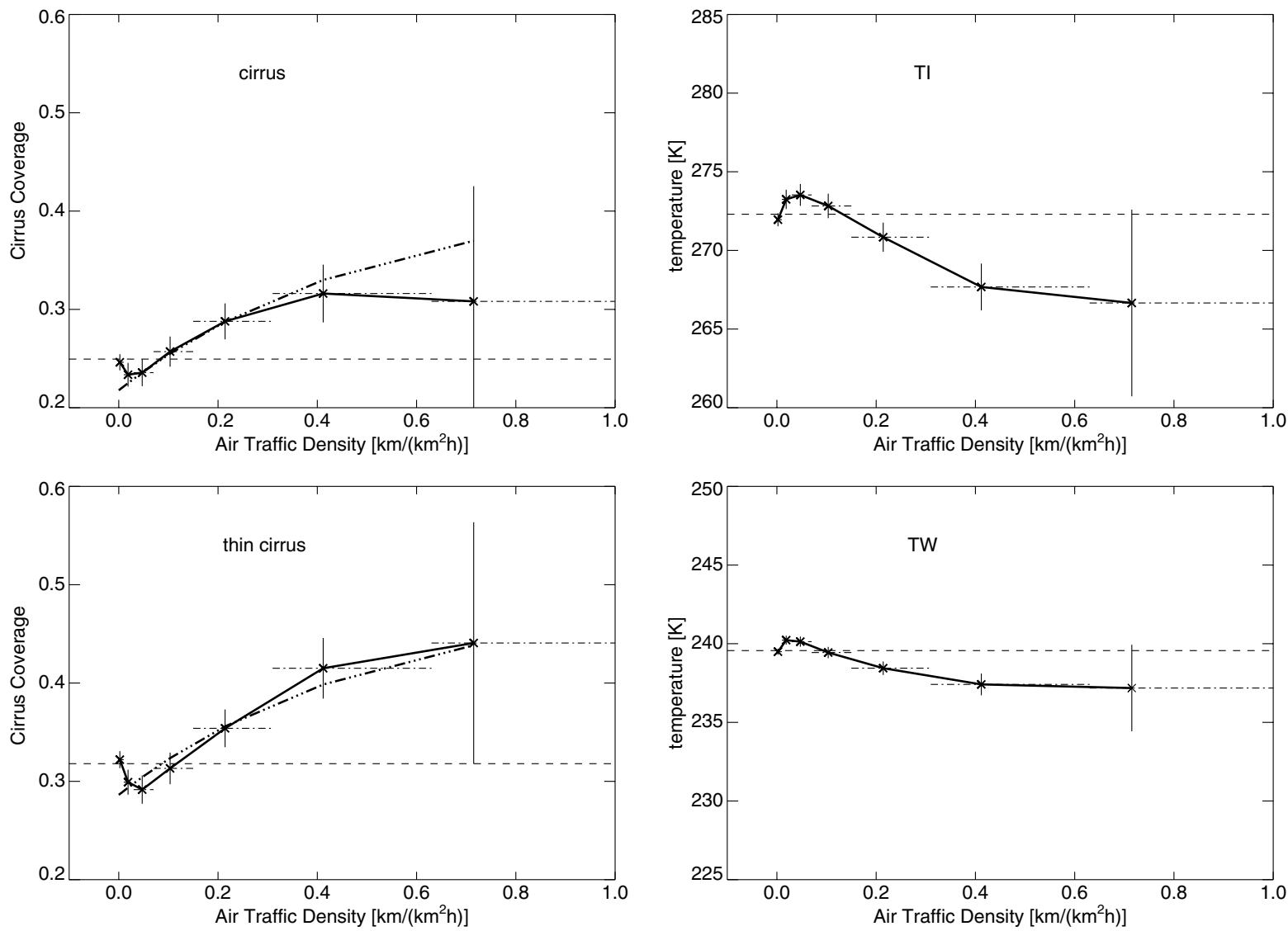

Figure 3: Cirrus coverage for two cirrus detection algorithms (left side) and equivalent mean black body temperature in the infrared (TI) and the water vapour (TW) channel of METEOSAT data (right side) as a function of air traffic density. The two different versions (top left and bottom left) of cirrus detection from METEOSAT data show a strong increase of cirrus cloudiness with increasing air traffic density. Plotted in each figure is the mean cirrus coverage within seven air traffic density classes indicated by the dash-dotted horizontal bars. The vertical bars indicate the range of statistical confidence at a $95 \%$ level derived from variance and number of independent observations for the single air traffic density classes, the horizontal dashed line the mean value of cloud coverage as defined by the algorithm. The theoretical cirrus coverage is indicated by the thick dash-dot-dotted curve.

anthropogenic influences correlating with air traffic. In this study, data on local cirrus properties derived by objective methods from satellite measurements are correlated with high-quality local air traffic data in the one hour time interval just before the cirrus was observed. Hence, the attribution of the observed cirrus changes to the effect of aviation is far more certain. The simple theoretical model (section 2) is consistent with the observed increase of cirrus cover with air traffic density (see Figure 3). This indicates that the observed cirrus change is mainly due to contrails spreading in ice supersaturated air masses. Hence our method determines the amount of the so-called "contrail cirrus" induced by air traffic. It does not identify the amount of cirrus changes induced by aviation aerosol (such as soot) far down-stream from the place of emission.

The analysis of linear contrails from NOAA14 AVHRR data for Central Europe (MEYER et al., 2002) using an automated contrail detection algorithm described in MANNSTEIN et al. (1999) results in a mean contrail coverage for the same period and nearly the same area of $0.3 \%$. Therefore it can be stated, that the coverage by additional cirrus clouds is in Europe about 10 times higher than by linear contrails. Further studies, with independent cirrus estimates and longer time periods of observations, are necessary to confirm the results of this study. Such studies are underway and meanwhile further analysis with new air traffic data for the year 2004 and cirrus coverage derived from METEOSAT-8 have been performed (to be published elsewhere) which support our results. The statistical method to derive the cirrus coverage depending on air traffic density does not allow to infer the optical properties of the aircraft induced cirrus clouds. Thus it is not possible to calculate their radiative impact without further information. The optical depth of these additional cirrus clouds cannot be less than 0.2 , the optical depth usually attributed to linear contrails, otherwise they would not be detected by METEOSAT. The radiative forcing increases with the optical depth of the cirrus (at least for moderately thick 
cirrus; see MEERKÖTTER et al., 1999). Optically thick cirrus is excluded in the 'thin cirrus test', and the difference between the two cirrus detection methods may be a measure for the fraction of thick cirrus. However, since we cannot exclude that the fraction of optically thick cirrus induced by aviation may have negative radiative forcing, the average radiative forcing of the additional cirrus clouds may be both smaller and larger than for linear contrails. A more accurate conclusion would require to determine the changes of both the solar and the terrestrial radiative fluxes induced by the air traffic. Our analysis of the equivalent black body temperature (see Figure 3) implies a reduction of outgoing infrared radiation in the direction towards the satellite sensor due to aviation induced cirrus but we have no data on the terrestrial flux integrated over all upward directions nor do we have the information on the change of solar flux related to air traffic. Moreover, this was a regionally and temporally restricted study. Hence, we can conclude only that the radiative effect of the aviation induced cirrus clouds may be more than 10 times the effect of the linear contrails.

The high amount of contrail cirrus compared to linear contrails indicates, that the lifetime of contrail cirrus has to be measured in hours rather than in minutes. This leads to an additional temporal effect, which has not been considered in previous studies. During daylight conditions the cooling effect of cirrus clouds due to enhanced reflection nearly balances the warming effect in the infrared part of the spectrum, while after sunset only the warming effect is remaining. The cloud coverage by cirrus clouds resulting from contrails has a considerable time lag behind the air traffic. Therefore part of the impact of air traffic over Europe is shifted to the night hours, where only the warming effect of cirrus clouds is remaining.

In future studies it will be necessary to consider a further, secondary contrail effect. The additional ice particles formed in contrails can either lead to an enhanced net sedimentation rate resulting in a dryer upper troposphere, or to a reduced one, as the particles formed in contrails are smaller and therefore slower. The details of these processes depend strongly on the vertical motion and the small scale structure of the moisture field in these altitudes, which are both not known sufficiently.

\section{References}

Bakan, S., M. Betancor-Gothe, V. Gayler, H. GRASSL, 1994: Contrail frequency over Europe from NOAA-satellite images. - Ann. Geophys. 12, 962-968.

Boucher, O., 1999: Air traffic may increase cirrus cloudiness. - Nature 397, 30-31.

Freudenthaler, V., F. Homburg, H. JÄGer, 1995: Contrail observations by ground-based scanning lidar: cross-sectional growth. - Geophys. Res. Lett. 22, 35013504

Gierens, K., U. Schumann, M. Helten, H. Smit, A. MARENCO, 1999: A distribution law for relative humidity in the upper troposphere and lower stratosphere derived from three years of MOZAIC measurements. - Ann. Geophys. 17, 1218-1226.

Gierens, K., U. Schumann, M. Helten, H. Smit, P. WANG, 2000: Ice-supersaturated regions and sub-visible cirrus in the northern midlatitude upper troposphere. - J. Geophys. Res. 105, 22,743-22,753.

Intergovernmental Panel on Climate Change (IPCC), 1999: Aviation and the Global Atmosphere. J. E. PEnner et al. (Eds.) - Cambridge Univ. Press, 373 pp.

LIOU, K.N., 1986: Influence of cirrus clouds on weather and climate processes: a global perspective. - Mon. Wea. Rev. 114, 1167-1198.

MAnnstein, H., R. Meyer, P. Wendling, 1999: Operational detection of contrails from NOAA-AVHRR-data. Int. J. Remote Sensing 20, 1641-1660.

MEYER, R., H. MAnNstein, R. MEERKötter,U. SCHUMANN, P. WENDLING, 2002: Regional radiative forcing by line-shaped contrails derived from satellite data. - J. Geophys. Res. 107, 10.1029/2001JD000426, ACL 17-1 - ACL 17-15.

MeErkötter, R., U. Schumann, P. Minnis, D.R. Doelling, T. NAKAJima, Y. Tsushima, 1999: Radiative forcing by contrails. - Ann. Geophys. 17, 1080-1094.

Minnis, P., D.F. Young, D.P. GARBER, L.N. NGUYEN, W.L. SMith JR., R. PALIKONDA, 1998: Transformation of contrails into cirrus during SUCCESS. - Geophys. Res. Lett. 25, 1157-1160.

SCHUMANN, U., 1996: On conditions for contrail formation from aircraft exhausts. - Meteorol. Z. 5, 4-23.

—, 2002: Contrail cirrus. - In: D. K. Lynch, K. Sassen, D. O’C. Starr, G. Stephens(Eds.): Cirrus. Oxford University Press, 231-255. 